\title{
EFEITO DE UM PROGRAMA DE RESSIGNIFICAÇÃO DA EDUCAÇÃO NO CLIMA ESCOLAR EM DUAS INSTITUIÇÕES DE EDUCAÇÃO FUNDAMENTAL - SÉRIES INICIAIS
}

\author{
Juliana Freire Bidóia ${ }^{1}$, Alessandra de Morais ${ }^{2}$, Cristiane Paiva Alves ${ }^{3}$, Patrícia Unger Raphael Bataglia ${ }^{4}$ \\ ${ }^{1}$ Mestre em Educação pela Universidade Estadual Paulista - UNESP, Programa de Pós - Graduação em Educação, \\ Marília, SP. ORCID iD: https://orcid.org/0000-0001-9560-5528. E-mail: julianafreire.bidoia@gmail.com. \\ ${ }^{2}$ Doutora em Educação pela Universidade Estadual Paulista - UNESP. Professora Assistente Doutora do Departamento \\ Psicologia da Educação - DPE e do Programa de Pós-Graduação em Educação - PPGE da Universidade Estadual Paulista \\ - UNESP, Marília, SP. ORCID iD: http://orcid.org/0000-0001-5521-9307. E-mail: alessandra.morais@unesp.br. \\ ${ }^{3}$ Doutora em Educação Especial pela Universidade Federal de São Carlos - UFSCar. Professora do Departamento de \\ Fisioterapia e Terapia Ocupacional - DEFITO da Universidade Estadual Paulista - UNESP, SP. ORCID ID: \\ http://orcid.org/0000-0002-2450-4129. E-mail: paiva.alves@unesp.br. \\ ${ }^{4}$ Doutora em Psicologia Social pela Universidade de São Paulo - USP. Professora Assistente Doutora do Departamento \\ Psicologia da Educação - DPE e do Programa de Pós-Graduação em Educação - PPGE da Universidade Estadual Paulista \\ - UNESP. ORCID iD: http://orcid.org/0000-0002-2575-3020. E-mail: patriciaurbataglia@gmail.com.
}

\section{RESUMO}

Este trabalho tem como tema um processo de ressignificação da educação tomando como um dos parâmetros de análise o clima escolar. Entende-se por ressignificação da educação o processo de reflexão da comunidade escolar a respeito dos fins e meios do processo de ensino-aprendizagem. Um instrumento que possibilita a identificação da percepção dos atores em relação ao ambiente escolar é o Questionário do Clima Escolar. Esta pesquisa teve como objetivo analisar os efeitos de um programa de ressignificação da educação na qualidade do clima escolar, sob a perspectiva de estudantes, em duas escolas públicas municipais de Educação Infantil e Ensino Fundamental. Como instrumento foi utilizado o Questionário de Avaliação do Clima Escolar. Trata-se de uma pesquisa quase experimental, em que para a constatação dos efeitos do processo de ressignificação sobre a qualidade do clima escolar realizou-se pré-teste e pós-teste, ambos com aplicação do referido questionário em aproximadamente 500 estudantes do 3 ao 50 ano. Fizeram parte da pesquisa três escolas públicas municipais, com características semelhantes, sendo duas das escolas pertencentes ao grupo experimental, com a interveniência da variável independente (programa de ressignificação) e a outra do grupo controle. Os resultados permitiram identificar as transformações significantes nas escolas experimentais em comparação com a escola do grupo controle. A conclusão do trabalho serviu como base para retroalimentar as ações do programa em pauta no momento da devolutiva do diagnóstico inicial (pré-teste), em que os educadores participaram ativamente do processo de reflexão sobre os resultados do clima.

Palavras-chave: Ressignificação da educação. Clima escolar. Educação fundamental. Séries iniciais.

\section{THE EFFECT ON SCHOOL CLIMATE QUALITY OF AN EDUCATION REFRAMING PROGRAM IN TWO ELEMENTARY EDUCATION INSTITUTION}

\section{ABSTRACT}

This work has as its theme a process of education reframing taking the school climate as one of its parameters of analysis. The reframing of the education is understood as a process of reflection of the school community regarding the aims and means of the teaching-learning process. An instrument that makes possible to identify the actors' perception of the school environment is the School Climate Questionnaire. This research aimed to analyze the effects on school climate quality of an education reframing program under the perspective of the students, in two municipal public schools of Early Childhood Education and Elementary Education. The School Climate Assessment Questionnaire was used as an instrument. It is a quasi-experimental research, in which to verify the effects of the reframing process on the school climate quality, a pre-test and a post-test were carried out, both with the application of the 
referred questionnaire to approximately 500 students from the 3 rd to 5 th grades. Three municipal public schools with similar characteristics were part of the research, two of them in the experimental group, with the intervention of the independent variable (reframing program) and the other one as the control group. The results allowed to identify the significant transformations in the experimental schools in comparison with the school of the control group. The conclusion of the work served to retro-analyze the actions of the program at the time of the initial diagnosis (pre-test) feedback, in which the educators actively participated the process of reflection on the results of the climate.

Keywords: Education reformulation. School climate. Elementary school.

\section{EFECTOS DEL CLIMA ESCOLAR EN EL PROGRAMA DE UNA NUEVA SIGNIFICACIÓN EDUCATIVA EN DOS ESCUELAS DE EDUCACIÓN PRIMARIA.}

\section{Resumen}

Este trabajo tiene como tema el proceso de una nueva formulación de la educación evidenciando el clima escolar como uno de los parámetros de análisis. Este nuevo planteamiento de la educación se entiende como el proceso de reflexión de la comunidad educativa con respecto a los objetivos y los medios del proceso de enseñanza-aprendizaje. Un instrumento que permite identificar la percepción de los actores del entorno escolar es el Cuestionario del clima escolar. Esta investigación tiene como objetivo principal analizar los efectos de un programa sobre una nueva formulación de la educación en la calidad del clima escolar, desde la perspectiva de los estudiantes, en dos escuelas públicas municipales de Educación Infantil y Educación Primaria. El cuestionario de evaluación del clima escolar se utilizó como instrumento. Es una investigación cuasi-experimental, donde sirve para verificar los efectos del proceso de reestructuración en la calidad del clima escolar, se realizaron una prueba previa y una prueba posterior, ambas con la aplicación del cuestionario en aproximadamente 500 estudiantes del 3er. 5to año. La investigación cuenta con tres escuelas públicas municipales, con características similares, dos de las cuales pertenecen al grupo experimental, con la influencia de la variable independiente (programa de reformulación) y la del grupo de control. Los resultados permitieron identificar las transformaciones relevantes en las escuelas experimentales en comparación con la escuela del grupo de control. La conclusión del trabajo sirve de base para retroalimentar las acciones del programa en cuestión al momento de devolver el diagnóstico inicial (pretest), en el que los educadores participaron activamente en el proceso de reflexión sobre los resultados del clima escolar.

Palabras clave: Reformulación de la educación. Clima escolar. Educación primaria. Calificaciones iniciales.

\section{INTRODUÇÃO}

O tema do presente estudo é mostrar os impactos de um projeto de ressignificação, por meio da avaliação do clima escolar. Ressignificar a educação tem o sentido de repensar os propósitos e métodos utilizados para alcançar tais propósitos no ato de educar. A educação vista como construtora da autonomia do estudante no sentido intelectual e moral não é materializada na maioria das escolas atualmente. Mizukami (2007) aponta, por exemplo, uma prevalência de relações verticalizadas, nas quais o professor é a autoridade intelectual e moral e o aluno seu submisso. A curiosidade do educando, as preferências, a inquietude não importam. 0 professor sabe o que é melhor, o que deve ser transmitido e como isso deve ser feito.

Ainda que exista um debate sobre esse modelo desde o movimento da Escola Nova, muito pouco temos avançado. Podemos hipotetizar que talvez essa forma de relação seja um valor de nossa cultura, ou seja, a hierarquização de conhecimentos e de posições tem, na história de nosso país, sido valorizada como algo necessário. Outra hipótese é a de que os professores não sabem como fazer diferente do modelo em que foram formados. Podemos pensar, ainda, que falta um estímulo à reflexão sobre se o que estamos alcançando no processo educativo é de fato o que pretendemos e se os métodos utilizados seriam eficientes para isso.

Em sua tese, após revisitar a obra de alguns pesquisadores da inovação educacional, Barrera (2016, p.24) realiza a intersecção de conceitos apresentados e cria a seguinte definição: "Inovação na educação é um processo intencional de mudança de uma prática educativa desenvolvida por um sujeito, grupo ou sociedade, 
que incorpora um ou mais aspectos novos a esta prática".

O processo de inovação educacional é sempre um ato coletivo. Segundo Pacheco (2019), em cada pessoa existe o potencial inovador, basta que o ambiente seja propício para seu desenvolvimento. A preparação de um ambiente propício a inovações e ressignificações se dá, portanto, pela re-formação das pessoas que constituem a escola. As reformas podem ocorrer nas relações interpessoais, no currículo, nos métodos, nos recursos e nas avaliações (FERRETI, 1980).

É nesse esteio que se pauta o trabalho realizado. A proposta desse processo de ressignificação escolar, partiu do educador Marcos Rogério Silvestri Vaz Pinto, que como parte de suas atividades de pós-graduação lato sensu juntamente a Universidade Federal do Paraná, construiu o intento de levar aos educadores a reflexão a respeito de quais os fins e meios da educação e se a práxis desenvolvida por eles coaduna com tais fins e meios (PINTO, 2018). Em suas considerações iniciais, o educador reflete a respeito do número de horas que os professores passam em formações e que mesmo assim, a qualidade do ensino em nosso país não é aprimorada. Ele aponta que o modo como o professor é formado/ensinado é o modo como ele forma/ensina, portanto, uma formação pautada na transmissão de conhecimentos, irrefletida, não surtirá efeitos práticos na atuação dos educadores. Pensando nisso, o educador propõe um programa que tem como início um trabalho baseado aos vínculos entre os educadores. Esse primeiro momento é chamado de acolhimento, no qual, visa o reconhecimento do trabalho que realizado em grupo, com o outro, surgindo uma interdependência que deve ser positiva.

O segundo momento é a construção da utopia. As questões diretrizes são: "o que não queremos mais ver nessa escola?" e "o que me impede de concretizar essa utopia?". Essa primeira pergunta é muito desestabilizadora. O que não queremos mais ter ou ver na escola são situações que poderíamos evitar se fizéssemos diferente? A segunda questão é igualmente provocadora: por que cada ator desse ambiente não faz por mudar a situação que incomoda?

O terceiro passo é de assunção de responsabilidade e, por conseguinte, de parar de culpabilizar o outro (seja ele quem for) pela inação de todos. Por fim, procede-se ao estabelecimento dos núcleos de ressignificação que são formados pelos educadores que tenham vontade de desenvolver o processo de inovação, em que juntos buscam referenciais teóricos para fundamentarem suas práticas, e analisá-las em um movimento contínuo de reflexão e transformação coletiva.

O processo de ressignificação foi iniciado em duas escolas municipais do interior do estado de São Paulo, há aproximadamente três anos. Os educadores têm se envolvido gradativamente nas ações e, com as dificuldades inerentes a qualquer processo de mudança, a ressignificação da educação tem acontecido. As autoras do presente artigo foram convidadas para acompanhar desde o início as atividades de formação dos educadores e várias formações teórico-práticas têm sucedido.

Uma ferramenta proposta para a avaliação dos resultados desse processo de ressignificação, foi o Questionário de Avaliação do Clima Escolar (VINHA; MORAIS; MORO, 2017). O clima escolar, no contexto das Ciências Sociais, refere-se a como os atores de determinada instituição percebem as relações entre si, como regras e infraestrutura. Nas palavras de Vinha, Morais e Moro (2017, p. 8),

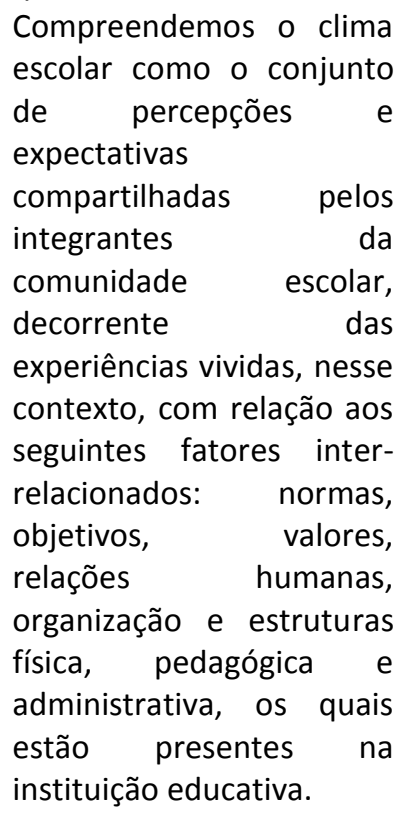

Cada criança ou adolescente traz consigo crenças, valores e costumes próprios de sua socialização primária. Por conseguinte, choques de diferentes realidades, culturas, ideais, gostos e personalidades ocorrem de forma corriqueira dentro do ambiente escolar, onde os estudantes estão aprendendo como funciona viver dentro de uma comunidade, com indivíduos semelhantes e 
diferentes uns dos outros. Desta forma, além do conteúdo didático a ser aprendido, o processo de ressignificação da educação abrange o desenvolvimento de consciência, de comunidade e estruturação das relações interpessoais dentro da escola.

O clima escolar está diretamente ligado às dinâmicas de convivência social construídas que possam determinar a qualidade de vida e a produtividade do estudante, bem como dos docentes e universo escolar como um todo.

Para avaliação do clima escolar Vinha, Morais e Moro (2017), em conjunto com pesquisadores de diferentes universidade brasileiras, elaboraram três instrumentos de pesquisa que se propõem a mensurar a percepção dos estudantes (de 70 ano ao Ensino Médio), educadores e gestores a respeito de várias dimensões que compõem o clima: as relações com o ensino e com a aprendizagem; as relações sociais e os conflitos na escola; regras, sanções e a segurança na escola; as situações de intimidação entre alunos; família, escola e comunidade; infraestrutura e a rede física da escola; as relações com o trabalho; e a gestão e a participação.

Entretanto, as escolas em que o processo de ressignificação aconteceu eram escolas municipais de Ensino Fundamental I o que exigiu uma adaptação dos instrumentos. A descrição pormenorizada da adaptação e levantamento dos indícios de validade da escala adaptada estão publicados em Castellini (2019).

Descreveremos abaixo a metodologia e resultados obtidos na avaliação do clima antes e após um período do trabalho de ressignificação.

\section{DELINEAMENTO METODOLÓGICO}

A pesquisa é de delineamento quase experimental, com abordagem quantitativa, em que se procurou avaliar os efeitos de um Programa de Ressignificação da Educação, desenvolvido em duas escolas públicas municipais (Escolas Experimentais I e II), na qualidade do clima escolar, avaliado sob a perspectiva dos estudantes. Consistiu em um diagnóstico inicial (pré-teste) e diagnóstico posterior (o qual doravante denominaremos de pós-teste), o último realizado aproximadamente um ano e três meses após o início do Programa de Ressignificação. Contou-se ainda com a participação de uma Escola Controle, em que não teve a interveniência da variável independente (Programa de Ressignificação da Educação), e que possui características semelhantes às escolas experimentais, no referente ao tipo de escola (pública municipal), nível de ensino (possuir os primeiros anos do Ensino Fundamental) e localização (mesmo município do interior do estado de São Paulo) .

O município no qual se situam as escolas localiza-se a nordeste da capital paulista, com uma população de aproximadamente 73.101 habitantes, e que possui, ainda, uma grande porcentagem de sua população vivendo em área rural. A Escola Experimental I, está localizada em uma área rural e possui cerca de 220 alunos. A Escola Experimental II, situa-se em um bairro periférico e possui aproximadamente 600 alunos. A Escola Controle, também está localizada em uma área rural, e tem cerca de 125 alunos.

Os sujeitos da pesquisa são os estudantes que no ano de 2018 estavam nos terceiros e quartos anos das três escolas, e no de 2019, respectivamente, nos quartos e quintos anos. A aplicação do questionário de avaliação do clima escolar ocorreu no mês de junho do ano de 2018 como pré-teste, e no mês de setembro de 2019, como pós-teste. Para a análise comparativa intragrupo, consideramos como participantes somente aquelas crianças que responderam ao pré e pós-testes. Desse modo, tal como pode ser observado na Tabela 1, a amostra definida para a análise foi de 50 crianças da Escola Experimental I, 174 crianças da Escola Experimental II e 18 crianças da Escola Controle. 
Tabela 1. Ano de matrícula e gênero das crianças participantes do pré e pós-testes na Escolas Experimentais e Controle

\begin{tabular}{|c|c|c|c|c|c|}
\hline \multicolumn{3}{|c|}{ Gênero das crianças participantes } & Menina & Menino & Total \\
\hline \multirow[t]{4}{*}{ Escola Experimental I } & \multirow[t]{2}{*}{40 ano } & Frequência & 18 & 14 & 32 \\
\hline & & $\%$ & $56,3 \%$ & $43,8 \%$ & $100,0 \%$ \\
\hline & \multirow[t]{2}{*}{ 5o ano } & Frequência & 10 & 8 & 18 \\
\hline & & $\%$ & $55,6 \%$ & $44,4 \%$ & $100,0 \%$ \\
\hline \multirow[t]{2}{*}{ Total } & & Frequência & 28 & 22 & 50 \\
\hline & & $\%$ & $56,0 \%$ & $44,0 \%$ & $100,0 \%$ \\
\hline \multirow[t]{4}{*}{ Escola Experimental II } & \multirow[t]{2}{*}{$4 \%$ ano } & Frequência & 66 & 62 & 128 \\
\hline & & $\%$ & $51,6 \%$ & $48,4 \%$ & $100,0 \%$ \\
\hline & \multirow[t]{2}{*}{ 5o ano } & Frequência & 18 & 28 & 46 \\
\hline & & $\%$ & $39,1 \%$ & $60,9 \%$ & $100,0 \%$ \\
\hline \multirow[t]{2}{*}{ Total } & & Frequência & 84 & 90 & 174 \\
\hline & & $\%$ & $48,3 \%$ & $51,7 \%$ & $100,0 \%$ \\
\hline \multirow[t]{4}{*}{ Escola Controle } & \multirow[t]{2}{*}{40 ano } & Frequência & 6 & 3 & 9 \\
\hline & & $\%$ & $66,7 \%$ & $33,3 \%$ & $100,0 \%$ \\
\hline & \multirow[t]{2}{*}{ 5o ano } & Frequência & 4 & 5 & 9 \\
\hline & & $\%$ & $44,4 \%$ & $55,6 \%$ & $100,0 \%$ \\
\hline \multirow{2}{*}{\multicolumn{2}{|c|}{ Total }} & Frequência & 10 & 8 & 18 \\
\hline & & $\%$ & $55,6 \%$ & $44,4 \%$ & $100,0 \%$ \\
\hline
\end{tabular}

Fonte: As autoras.

Nota: Elaborada com dados da pesquisa.

O recurso utilizado para a avaliação do clima escolar é um questionário específico, voltado para a realidade escolar brasileira e adaptado para o Ensino Fundamental I, que avalia as seguintes dimensões, na perspectiva dos estudantes: relações com o ensino e a aprendizagem; relações sociais e os conflitos; regras, sanções e segurança; situações de intimidação entre os alunos, relações entre a família, comunidade e a escola e infraestrutura e a rede física da escola. Tal questionário foi adaptado por uma equipe de pesquisadores, com base em instrumento construído e validado para estudantes dos $7^{\circ}$ anos do Ensino Fundamental a 3a séries do Ensino Médio das escolas públicas brasileiras. (VINHA; MORAIS; MORO, 2017).

Além da avaliação do clima escolar, foram realizadas as reuniões de devolutiva reflexiva entre as pesquisadoras e a equipe docente e gestora de cada uma das escolas participantes. A primeira reunião foi feita em março de 2019, tendo-se como pauta os resultados do pré-teste, e contou com a presença dos docentes e gestores das Escolas Experimentais, e da gestão da Escola Controle. A segunda reunião ocorreu em fevereiro de 2020, e nela foram discutidos os resultados do pós-teste. Nesse momento houve a participação das equipes docente e gestora das Escolas Experimentais. Participaram das reuniões, aproximadamente, 15 professores e 3 gestores da Escola Experimental I, 30 professores e 5 gestores da Escola Experimental II, e um gestor da Escola Controle. Ressaltamos que nos ateremos aos dados da devolutiva com as Escolas Experimentais.

Para realização da pesquisa houve o parecer favorável do Comitê de Ética em Pesquisa da instituição a qual o projeto se vincula (CAAE: 46505415.8.0000.5406).

Para a análise quantitativa foi utilizada a estatística descritiva (média, mediana e frequências absoluta e relativa) e inferencial (Teste dos Postos com Sinais de Wilcoxon para dados pareados, considerando-se o valor de significância de $p$ menor ou igual a 0,05). Avaliouse a qualidade do clima escolar em suas 
diferentes dimensões, de modo a se realizar comparações intragrupo, entre o pré e póstestes, nas Escolas Experimentais I e II e na Escola Controle.

\section{RESULTADOS E DISCUSSÃO}

Apresentamos os resultados obtidos pela avaliação do clima escolar, a partir da perspectiva dos alunos da Escola Experimental I, Escola Experimental II e da Escola Controle, os quais são explicitados por meio de comparações entre os dados obtidos no pré-teste e pós-teste.

$\mathrm{Na}$ Tabela 2, podemos visualizar os resultados alcançados pela Escola Experimental I, no referente às Dimensões do Clima, com destaque àquelas que apresentaram diferenças significantes entre o pré e pós-teste.

Tabela 2. Escola Experimental I: comparações entre as médias e medianas obtidas no pré e pós-testes nas diferentes dimensões do clima escolar.

\begin{tabular}{|c|c|c|c|c|c|c|c|}
\hline $\begin{array}{l}\text { Dimensões do } \\
\text { clima }\end{array}$ & $\begin{array}{l}\text { Pré } \\
\text { Média }\end{array}$ & $\begin{array}{l}\text { Pós } \\
\text { Média }\end{array}$ & $\begin{array}{l}\text { Pré } \\
\text { Mediana }\end{array}$ & $\begin{array}{l}\text { Pós } \\
\text { Mediana }\end{array}$ & $\mathrm{Z}^{1}$ & $\mathbf{P}^{2}$ & Comentário \\
\hline $\begin{array}{l}\text { Dimensão } 1 \text { - As } \\
\text { relações com o } \\
\text { ensino e com a } \\
\text { aprendizagem. }\end{array}$ & 2,7862 & 3,1246 & 2,8462 & 3,1538 & $-5,256$ & 0,000 & pré < pós \\
\hline $\begin{array}{c}\text { Dimensão } 2 \text { - As } \\
\text { relações sociais } \\
\text { e os conflitos na } \\
\text { escola. }\end{array}$ & 3,1271 & 3,1700 & 3,1429 & 3,2143 & $-0,832$ & 0,405 & pré = pós \\
\hline $\begin{array}{c}\text { Dimensão } 3 \text { - As } \\
\text { regras, as } \\
\text { sanções e a } \\
\text { segurança na } \\
\text { escola. }\end{array}$ & 2,7982 & 3,0027 & 2,7955 & 2,9545 & $-4,290$ & 0,000 & pré < pós \\
\hline $\begin{array}{c}\text { Dimensão } 4 \text { - As } \\
\text { situações de } \\
\text { intimidação } \\
\text { entre alunos. }\end{array}$ & 3,3453 & 3,3600 & 3,4000 & 3,4000 & $-0,132$ & 0,895 & pré = pós \\
\hline $\begin{array}{l}\text { Dimensão } 5 \text { - A } \\
\text { família, a escola } \\
\text { e a comunidade. }\end{array}$ & 2,6180 & 2,5600 & 2,6500 & 2,5000 & $-0,539$ & 0,590 & pré = pós \\
\hline $\begin{array}{c}\text { Dimensão } 6 \text { - A } \\
\text { infraestrutura e } \\
\text { a rede física da } \\
\text { escola }\end{array}$ & 2,8343 & 2,6914 & 2,8571 & 2,5714 & $-1,434$ & 0,152 & pré = pós \\
\hline
\end{tabular}

Podemos constatar que as Dimensões que apresentaram diferenças significantes foram a Dimensão 1 (As relações com o ensino e com a aprendizagem) e a Dimensão 3 (As regras, as sanções e a segurança na escola), em que as médias e medianas obtidas no pós-teste foram superiores àquelas alcançadas no pré-teste.
Pode-se afirmar, portanto, que houve uma avaliação mais positiva do clima escolar pelas crianças participantes, após o processo de ressignificação, no que diz respeito a essas dimensões. Por outro lado, na avaliação geral das demais dimensões, não foram encontradas 
diferenças significantes entre os resultados do pré e pós-testes.

$\mathrm{Na}$ tabela a seguir observamos os resultados referentes à Escola Experimental II.

Tabela 3. Escola Experimental II: comparações entre as médias e medianas obtidas no pré e pós teste nas diferentes dimensões do clima escolar.

\begin{tabular}{|c|c|c|c|c|c|c|c|}
\hline $\begin{array}{l}\text { Dimensões do } \\
\text { clima }\end{array}$ & $\begin{array}{l}\text { Pré } \\
\text { Média }\end{array}$ & $\begin{array}{l}\text { Pós } \\
\text { Média }\end{array}$ & $\begin{array}{c}\text { Pré } \\
\text { Mediana }\end{array}$ & $\begin{array}{c}\text { Pós } \\
\text { Mediana }\end{array}$ & $\mathrm{Z}^{1}$ & $\mathbf{P}^{2}$ & Comentário \\
\hline $\begin{array}{l}\text { Dimensão } 1 \text { - As } \\
\text { relações com o } \\
\text { ensino e com a } \\
\text { aprendizagem. }\end{array}$ & 2,7467 & 2,8627 & 2,7692 & 2,8462 & $-3,934$ & 0,000 & pré < pós \\
\hline $\begin{array}{l}\text { Dimensão } 2 \text { - As } \\
\text { relações sociais } \\
\text { e os conflitos na } \\
\text { escola. }\end{array}$ & 3,1365 & 3,0789 & 3,2143 & 3,0714 & $-1,509$ & 0,131 & pré = pós \\
\hline $\begin{array}{lrr}\text { Dimensão } & 3 \text { - As } \\
\text { regras, } & & \text { as } \\
\text { sanções e } & \text { a } \\
\text { segurança } & \text { na } \\
\text { escola. } & & \\
\end{array}$ & 2,7695 & 2,7481 & 2,7727 & 2,7727 & $-0,501$ & 0,616 & pré = pós \\
\hline $\begin{array}{l}\text { Dimensão } 4 \text { - As } \\
\text { situações de } \\
\text { intimidação } \\
\text { entre alunos. }\end{array}$ & 3,3322 & 3,3123 & 3,4000 & 3,3333 & $-0,775$ & 0,438 & pré = pós \\
\hline $\begin{array}{l}\text { Dimensão } 5 \text { - A } \\
\text { família, a escola } \\
\text { e a comunidade. }\end{array}$ & 2,4718 & 2,5602 & 2,4000 & 2,6000 & $-2,001$ & 0,045 & pré < pós \\
\hline $\begin{array}{l}\text { Dimensão } 6 \text { - A } \\
\text { infraestrutura e } \\
\text { a rede física da } \\
\text { escola }\end{array}$ & 2,7885 & 2,8713 & 2,7143 & 2,8571 & $-1,739$ & 0,082 & pré = pós \\
\hline
\end{tabular}

${ }^{1} \mathrm{Z}=$ valor da estatística do Teste dos Postos com Sinais de Wilcoxon para dados pareados;

${ }^{2} p$ = probabilidade de se observar um resultado tão ou mais extremo que o da amostra, supondo que a hipótese nula seja verdadeira

Fonte: As autoras.

Nota: Elaborada com dados da pesquisa.

A partir da comparação entre os resultados do pré-teste e pós-teste nas diferentes Dimensões do clima escolar, observamos que as dimensões que apresentaram diferenças significantes foram a Dimensão 1 - As relações com o ensino e com a aprendizagem, e a Dimensão 5 - A família, a escola e a comunidade, em que as médias e medianas coletadas na avaliação do clima escolar, no pós-teste, foram superiores do que aquelas alcançadas no préteste. Concluindo-se, que houve uma avaliação do clima escolar mais positiva, a partir do processo de ressignificação, focalizando em mudanças realizadas a respeito a essas dimensões. Mas, também verificamos que na avaliação geral das demais dimensões, não foram encontradas diferenças significantes entre os resultados obtidos no pré-teste e pós-teste.

$\mathrm{Na}$ Tabela 4, podemos observar os resultados coletados na Escola Controle, escola que não participou do Processo de Ressignificação da educação. 
Tabela 4. Escola Controle: comparações entre as médias e medianas obtidas no pré e pós-testes nas diferentes dimensões do clima escolar.

\begin{tabular}{|l|c|c|c|c|c|c|c|}
\hline $\begin{array}{c}\text { Dimensões do } \\
\text { clima }\end{array}$ & $\begin{array}{c}\text { Pré } \\
\text { Média }\end{array}$ & $\begin{array}{c}\text { Pós } \\
\text { Média }\end{array}$ & $\begin{array}{c}\text { Pré } \\
\text { Mediana }\end{array}$ & $\begin{array}{c}\text { Pós } \\
\text { Mediana }\end{array}$ & $\mathbf{Z}^{\mathbf{1}}$ & $\mathbf{P}^{\mathbf{2}}$ & Comentário \\
\hline $\begin{array}{l}\text { Dimensão 1 - As } \\
\text { relações com o } \\
\text { ensino e com a } \\
\text { aprendizagem. }\end{array}$ & 2,8205 & 2,9188 & 2,8077 & 2,9231 & 1,170 & 0,242 & pré = pós \\
\hline $\begin{array}{l}\text { Dimensão 2 - As } \\
\text { relações sociais } \\
\text { e os conflitos na } \\
\text { escola. }\end{array}$ & 3,4444 & 3,2991 & 3,4286 & 3,2857 & 1,458 & 0,145 & pré = pós \\
\hline $\begin{array}{l}\text { Dimensão 3 - As } \\
\text { regras, as } \\
\text { sanções e a } \\
\text { segurança na } \\
\text { escola. }\end{array}$ & 2,8965 & 2,8743 & 2,9091 & 2,8636 & 0,285 & 0,776 & pré = pós \\
\hline $\begin{array}{l}\text { Dimensão 4 - As } \\
\text { situações de } \\
\text { intimidação } \\
\text { entre alunos. }\end{array}$ & 3,4593 & 3,4778 & 3,5000 & 3,5333 & 0,261 & 0,794 & pré = pós \\
\hline $\begin{array}{l}\text { Dimensão 5 - A } \\
\text { família, a escola } \\
\text { e a comunidade. }\end{array}$ & $\mathbf{2 , 8 7 2 2}$ & $\mathbf{2 , 6 0 0 0}$ & $\mathbf{2 , 9 0 0 0 0}$ & $\mathbf{2 , 8 0 0 0}$ & $\mathbf{2 , 0 6 7}$ & $\mathbf{0 , 0 3 9}$ & pré > pós \\
\hline $\begin{array}{l}\text { Dimensão 6 - A } \\
\text { infraestrutura e } \\
\text { a rede física da } \\
\text { escola }\end{array}$ & 3,0476 & 2,7698 & 3,0000 & 2,7857 & 1,635 & 0,102 & pré = pós \\
\hline
\end{tabular}

${ }^{1} \mathrm{Z}$ = valor da estatística do Teste dos Postos com Sinais de Wilcoxon para dados pareados;

${ }^{2} p$ = probabilidade de se observar um resultado tão ou mais extremo que o da amostra, supondo que a hipótese nula seja verdadeira

Fonte: As autoras.

Nota: Elaborada com dados da pesquisa.

De acordo com a comparação entre os resultados do pré e pós-testes nas diferentes dimensões do clima escolar, constata-se que a Dimensão que apresentou diferença significante foi a Dimensão 5 - A família, a escola e a comunidade, porém, diferentemente do ocorrido nas escolas experimentais, as médias e medianas obtidas no pós-teste foram inferiores àquelas alcançadas no pré-teste. Podendo-se afirmar, portanto, que houve uma avaliação mais negativa do clima escolar pelas crianças participantes, no que diz respeito a essa Dimensão. Na avaliação geral das demais dimensões, não foram encontradas diferenças significantes entre os resultados do pré e pós-testes.

Portanto, através dessas análises, podemos constatar que as Escolas Experimentais
I e II, onde aconteceram e acontece o processo de Ressignificação da Educação, teve avanços significativos no pós- teste, caracterizando uma melhora importante no clima escolar. Enquanto, a Escola Controle, que não participou do referido programa, manteve-se praticamente com os mesmos resultados no pré e pós-testes, tendo apenas mudança em uma Dimensão, na qual demonstrou uma piora nos escores do pós-teste.

Chamamos a atenção para o fato de que as duas Escolas Experimentais mostraram resultados significantes na Dimensão 1 "Relações com o ensino e aprendizagem", podendo-se dar destaque aos seguintes itens: "item 2 - Na minha Escola os professores dão nota baixa quando os alunos não se comportam bem", sendo observada uma avaliação mais positiva por parte 
dos alunos, ao percebem que os professores diminuíram o uso da nota como forma de sanção expiatória e de controle dos comportamento dos alunos; "item 5 - Quando não entendem alguma coisa, podem perguntar para os professores várias vezes até entenderem", demonstrando que os professores passaram a ser mais atenciosos e solícitos com os alunos, dando-lhes a liberdade de perguntarem por diversas vezes algo que não entenderam; "item 7 - Montam grupos para fazer as atividades"; que indica o uso de práticas pedagógicas mais cooperativas, como a formação de grupos para o desenvolvimento das atividades; "item 8 - Perguntam o que vocês querem aprender na Escola", de modo a destacar que os alunos estão possuindo maior liberdade para expressarem o que realmente querem aprender, instigando-os a envolver os seus conhecimentos prévios com o conteúdo que será mediado pelo professor; "item 9 - Ajudam as crianças da sala para que todos aprendam"; que demonstra a percepção por parte dos estudantes de que os docentes da unidade escolar pesquisada, estão mais atenciosos e preocupados com o aprendizado e desenvolvimento de todos seus alunos; e para finalizar o "item 12 - Fazem atividades com os estudantes usando a internet", esclarecendo-se que tal item obteve um resultado bastante significativo devido ao impacto do programa de ressignificação escolar, uma vez que foi realizado um esforço conjunto por parte do corpo docente e gestor para que fosse proporcionado o acesso à internet aos seus alunos, a fim de apoiá-los nas atividades escolares e de pesquisas. Assim, a partir da análise dos itens com diferenças significantes da Dimensão 1 , podemos ver claramente que o processo de Ressignificação da Educação gerou um impacto positivo na avaliação dessa dimensão do clima escolar pelos estudantes, favorecendo o desenvolvimento de práticas pedagógicas mais ativas, cooperativas e que contemplem todos os alunos.

Ainda como resultados da pesquisa, incluem-se os dois momentos de devolutiva reflexiva dos dados de avaliação do clima escolar. O primeiro momento, teve como propósito a apresentação e reflexão coletiva sobre o diagnóstico inicial do clima (pré-teste). Nessa devolutiva, os docentes e gestores da Escola Experimental I e da Escola Experimental II foram separados, para que cada escola se voltasse para seu resultado (uma vez que o clima escolar é único e traz especificidades daquela escola em análise). Em seguida, os integrantes de cada escola foram divididos em grupos heterogêneos de quatro membros, buscando-se mesclar os gestores com os professores e, também, os professores de diferentes anos de ensino. Para cada grupo foi atribuída a tarefa de analisar os gráficos com os resultados dos itens de uma dimensão do clima, dentre as seis avaliadas. Também foi fornecido um roteiro que orientasse a análise, de modo a promover diferentes reflexões sobre os dados do clima obtidos naquela escola, dentre elas: quais os pontos positivos e que apontam para potencialidades; quais os negativos e que indicam fragilidades; quais ações poderiam ser organizadas a partir dos dados encontrados para melhorar o clima da escola, dentre outras observações e contribuições que quisessem levantar.

Todos os grupos de trabalho mostraramse envolvidos com a atividade e analisaram cada um dos pontos levantados no roteiro, sendo possível identificar e discutir sobre aqueles aspectos que ainda se apresentavam frágeis, em especial as relações como a família e a comunidade, discutindo-se as dificuldades de integração família-escola. Outro ponto levantado como fragilidade foi o não reconhecimento, por parte dos alunos, das situações de conflito e bullying na escola, o que motivou os docentes e gestores a pensarem em ações de sensibilização e intervenção. Como pontos positivos, os participantes relataram já estarem desenvolvendo práticas pedagógicas diferenciadas e ativas, como o trabalho com projetos e grupos de aprendizagem cooperativa, o que certamente já traria dados diferentes na próxima avaliação do clima escolar. Também mencionaram o desenvolvimento de práticas morais deliberativas, como rodas de conversa e assembleias de sala, voltadas para a discussão dos problemas de convivência e construção e discussão das regras (PUIG, 2000). Salientaram, ainda, que trabalhariam para aprimorarem tais práticas, e assim o fizeram, tal como foi possível constatar nos resultados comparativos entre o pré e pós-teste e que foram apresentados no segundo momento da devolutiva, sobre o qual relatamos na sequência.

Dessa forma, na segunda reunião, que consistiu na devolutiva dos dados do pós-teste, houve a apresentação para cada Escola Experimental das dimensões do clima e seus itens que tiveram melhora significante em relação ao pré-teste, assim como daqueles itens em que não 
foram identificadas mudanças. Novamente, os docentes e gestores foram divididos em grupos heterogêneos, e com base naqueles pontos do clima identificados como passíveis de aprimoramento, levantaram ações a serem realizadas, dentre as quais: rodas de conversa, assembleias e projetos que envolvam a participação das famílias; atividades de conscientização para que que todos cuidem melhor do seu ambiente escolar; conscientização sobre a importância de construção coletiva das regras e seu cumprimento pelos membros da comunidade escolar, dentre outras. Além disso, os participantes puderam identificar e reconhecer aqueles aspectos que demonstraram melhorias em decorrência do Programa de Ressignificação.

Com base nos dados apresentados, pudemos constatar que as Dimensões avaliadas do clima escolar são de grande importância para a compreensão das relações e do contexto interno da escola. Haja vista, que os itens que compõem as Dimensões, podem caracterizar um ambiente favorável (positivo) ou desfavorável (negativo) (VINHA; MORAIS; MORO, 2017).

Assim procuramos compreender os resultados considerados "positivos", obtidos durante o processo de Ressignificação da Educação, nas escolas participantes (Experimental I e Experimental II). Após a coleta dos dados nas Escolas Experimentais, foi realizada a análise estatística, pela qual comparamos os resultados obtidos no pré-teste (junho/2018) início do Programa de Ressignificação, com os resultados coletados no pós-teste (setembro/2019). Nessa análise pudemos constatar mudanças significativas com relação aos dados da Escola Experimental I, sendo que as Dimensões que obtiveram diferenças significantes foram: a Dimensão 1 "As relações com o ensino e com a aprendizagem" e a Dimensão 3 - "As regras, as sanções e a segurança na escola" , e na Escola Experimental II, a Dimensão 1 - "As relações com o ensino e com a aprendizagem" e a Dimensão 5 - "A família, a escola e a comunidade". Enquanto, na Escola Controle, onde não houve o processo de Ressignificação, não observamos melhorias significativas na qualidade do clima escolar, entre os dados do pré-teste e pós-teste. $O$ que nos afirma que o Programa de Ressignificação da Educação traz benefícios para a escola, tornandoa um ambiente mais cooperativo e democrático. Porém, ressaltamos que as melhorias/mudanças significantes observadas nas duas Escolas Experimentais, foram no referente a algumas das dimensões do clima escolar, não se estendendo a todas aquelas avaliadas pelo instrumento.

Em consequência, nas Escolas Experimentais I e II, os itens das Dimensões 1, 3 e 5 que apresentaram diferenças significantes nos afirmam que com a realização do Projeto de Ressignificação da Educação, o clima escolar passou a ser caracterizado como mais positivo, pois a escola adotou trabalhos com projetos que são voltados à realidade da comunidade e ao interesse do aluno; passou a realizar assembleias e rodas de conversas, voltadas para a construção e discussão das regras de convívio social, em parceria com os alunos; promoveu ações que visam maior liberdade e autonomia aos alunos para circular nos diferentes espaços da escola; desenvolveu ações visando maior integração e a melhor convivência entre professores e demais membros da comunidade escolar; diminuiu a aplicação de sanções expiatórias (castigos), entre outras mudanças que favorecem a construção de um clima escolar considerado mais positivo. Porém, a avaliação do clima escolar nos mostrou, que além de caracterizar os pontos positivos também nos aponta os aspectos que ainda precisam ser melhorados, levando-nos afirmar que as novas alternativas educacionais implicam em um processo contínuo de reflexão e transformação das práticas pedagógicas pelos diferentes membros da comunidade escolar (MESSINA, 2001; CAMPOLINA, 2012).

\section{CONSIDERAÇÕES FINAIS}

A ideia colocada pelo educador Marcos Rogério Pinto (PINTO, 2018) de que resultados diferentes na educação exigiam processos de formação de educadores também diferentes repercutiu em nosso grupo de pesquisa. A educação integral, ou uma nova educação deve superar o tradicionalismo, deve buscar novos métodos que possam despertar em cada educando assim como em cada educador o desejo e a vontade de aprender, de construir. Pudemos presenciar na devolutiva da primeira avaliação do clima o entusiasmo e a vontade de fazer melhor. Na segunda devolutiva, a surpresa feliz com os resultados e ao mesmo tempo as expressões de confirmação de que as crianças estão aprendendo mais, estão mais felizes e um resultado interessante: as professoras relatavam menor cansaço. 
Conhecemos os vários estudos a respeito do desgaste imenso percebido pelos educadores ao final do ano (ASSUNÇÃO; BARRETO; GASPARINI, 2005; CARLOTTO; SILVA, 2003; GOULART JUNIOR; LIPP, 2008 dentre outros). Oliveira (2000) relata inclusive que o mito associado por muitos professores de educação básica se assemelha ao mito de Sísifo que exercia um trabalho infindável por um castigo recebido dos deuses. Ele tinha que empurrar uma pedra montanha acima e ela rolava montanha abaixo. Pois bem, os nossos educadores das escolas do grupo experimental relataram ao final do ano satisfação, prazer e disposição.

Ainda que não tivéssemos detectado melhora significativa do clima por parte dos educandos, esse relato dos professores seria suficiente para considerarmos bem sucedido $o$ trabalho de ressignificação que está em andamento nas escolas parceiras. Mas, devemos ressaltar, que as crianças também reportam que são mais ouvidas, que acontecem rodas de conversa e momentos de decisão coletiva, que os conflitos têm sido mais trabalhados na hora e por meio do diálogo, que recursos de trabalhos em grupo e pesquisas têm sido mais incentivados, dentre outros itens que foram significativamente melhor pontuados no pós-teste.

Há muito trabalho a ser feito ainda, por exemplo, os funcionários têm sido convidados a participar das formações, mas não consideramos que compreendam plenamente a importância que sua intervenção tem no processo educativo; as famílias e a comunidade em geral tem participado de poucos projetos da escola, embora isso já tenha melhorado; há que se trabalhar nas relações sociais entre as crianças, principalmente considerando a existência de intimidações entre pares e uma certa inconsciência em relação a diversidade étnicaracial e de gêneros. Mas concordamos com Freire (2016) quando diz que

(...)os homens são seres capazes de se superar, que vão adiante e olham o futuro; seres para os quais a imobilidade representa um risco fatal, para os quais olhar o passado deve ser apenas um modo de compreender com maior clareza quem eles são e o que são para poder construir o futuro com mais sabedoria (FREIRE, 2016, p. 134).

\section{AGRADECIMENTOS}

Agradecemos às escolas parceiras que permitiram o acompanhamento do trabalho de ressignificação da educação, assim como aos membros do GEPPEl (Grupo de Estudos e Pesquisas em Psicologia Moral e Educação Integral) que participaram da coleta e tabulação dos dados apresentados neste texto. Os autores declaram não haver qualquer potencial conflito de interesse que possa interferir na imparcialidade deste trabalho científico.

\section{REFERÊNCIAS}

ASSUNÇÃO, A. A.; BARRETO, S. M.; GASPARINI, S. M. O professor, as condições de trabalho e os efeitos sobre sua saúde. Educação e Pesquisa, São Paulo, v. 31, n. 2, p. 189-199, mai./ago. 2005. Disponível em: http://www.scielo.br/pdf/ep/v31n2/a03v31n2.p df. Acesso em: 12 mai. 2018.

BARRERA, T.G.S. O movimento brasileiro de renovação educacional no início do século XXI. 2006, 276 f. Tese (Doutorado em Educação) Faculdade de Educação da Universidade de São Paulo, São Paulo, 2016.

CAMPOLINA, L. O. Inovação educativa e subjetividade: a configuração da dimensão histórico-subjetiva implicada em um projeto inovador. 2012. 228f. Tese (Doutorado em Educação) - Universidade de Brasília, Brasília, DF, 2012.

CARLOTTO, M. S., SILVA, G. N. Síndrome de Burnout: um estudo com professores da rede pública. Psicologia Escolar e Educacional, Maringá, v. 7, n. 2, p. 145-153, jun./out. 2003. Disponível em: http://www.scielo.br/pdf/pee/v7n2/n2a04.pdf. Acesso em: 05 fev. 2019.

CASTELLINI, T. S. J. Clima escolar e desempenho em avaliação externa: adaptação de um instrumento de avaliação do clima e relação com os resultados obtidos em provas externas municipais. 2019. 102f. Dissertação (Mestrado em Educação) - Faculdade de Filosofia e Ciências, Universidade Estadual Paulista, Marília, SP. 2019. 
FERRETTI, C. A inovação na perspectiva pedagógica. In: GARCIA, Walter. Inovação educacional no Brasil: problemas e perspectivas. São Paulo: Cortez: Autores Associados, 1980. p. 55-82.

FREIRE, P. Conscientização. Tradução de Tiago José Risi Leme. São Paulo: Cortez, 2016.

GOULART JUNIOR, E., LIPP, M.E.N. Estresse entre professoras do ensino fundamental de escolas públicas estaduais. Psicologia em Estudo, Maringá, v. 13, n. 4, p. 847-857, out./dez. 2008. Disponível

em:

http://www.scielo.br/pdf/pe/v13n4/v13n4a23.p df. Acesso em: 05 fev. 2019. DOI: 10.1590/S1413$\underline{73722008000400023}$

MESSINA, G. Mudança e Inovação Educacional: notas para reflexão. Cadernos de Pesquisa, São Paulo, n. 144, p. 225-233, 2001. Disponível em: https://www.scielo.br/scielo.php?script=sci artte xt\&pid=S0100-

15742001000300010\&lng=pt\&t|ng=pt. Acesso em: 05 fev. 2019. DOI: 10.1590/S010015742001000300010

MIZUKAMI, M. da G. N. Ensino: as abordagens do processo. São Paulo: EPU, 2007.

OLIVEIRA, M.F. Contribuições da teoria analítica para a psicopedagogia - busca de uma abordagem relacional professor-aluno. 2000. 77 f. Monografia (Aperfeiçoamento/Especialização em Psicopedagogia) - Faculdades Costa Braga, São Paulo, 2000.

PACHECO, J. Inovar é assumir um compromisso ético com a educação. Petrópolis, Rio de Janeiro: Editora Vozes, 2019.

PINTO, M.R.S.V. Transformação vivencial e os caminhos para a ressignificação escolar. 2018. Memorial (Especialização em Alternativas para uma Nova Educação) - Universidade Federal do Paraná, Matinhos, 2018.

PUIG, J. M. Práticas morais: uma abordagem sociocultural da Educação Moral. São Paulo: Editora Moderna, 2000.

VINHA, T. P.; MORAIS, A..; MORO, A. (Orgs.) Manual de orientação para a aplicação dos questionários que avaliam o clima escolar. Campinas, SP: FE/UNICAMP, 2017. 